\title{
Development, delivery and evaluation of a social work elective offered in a hospital setting
}

\section{Barbara Muskat ${ }^{1}$, Samantha Anthony ${ }^{2}$, Faye Mishna ${ }^{3}$, and Andrea Greenblatt ${ }^{1}$}

\begin{abstract}
This paper describes a qualitative study about a Master's level elective course offered on-site at a Canadian pediatric hospital and delivered by frontline hospital social workers. Ten social workers and four students participated in the study which captured their experiences in the course. A grounded theory approach guided this study. Social workers discussed an enhanced sense of professional self, impact on their daily roles and various opportunities resulting from participation. Students discussed diversity, development of a realistic understanding of the social work role and the unique format of the course. Implications for future course development and university-agency partnerships are discussed.
\end{abstract}

Keywords: social work; education; pediatrics; hospital; teaching

1. Department of Social Work, The Hospital for Sick Children, Toronto / FactorInwentash Faculty of Social Work, University of Toronto

2. Child Health Evaluative Sciences, The Hospital for Sick Children, Toronto / Factor-Inwentash Faculty of Social Work, University of Toronto

3. Factor-Inwentash Faculty of Social Work, University of Toronto

Address for correspondence: barbara.muskat@sickkids.ca

Date of first (online) publication: 18th January 2017

Acknowledgement: Funding for this research was provided by the Bertha Rosenstadt Trust Fund in Health Research, Factor-Inwentash Faculty of Social Work, University of Toronto, Canada

63 J. of Practice Teaching \& Learning 15(1), pp.63-80. ๑ w\&b 


\section{Introduction}

Hospital health care delivery has faced rapid and frequent change over the past two decades, requiring hospital social workers to continually adapt their practices. Hospital staff, including social workers, face a myriad of issues including: increasing funding shortages and spending caps, complex and chronic patient conditions, increased social and environmental-based illnesses and pressures to measure health care delivery outcomes (Berkman, Phillips \& Stein, 2003; Naylor \& Naylor, 2012; Volland, 1996; Volland et al, 2003). Hospital social workers practice in acute or chronic care settings, providing emotional and instrumental support to patients and connecting them with both internal and external resources. Social workers approach their work from a systems perspective and view patients as embedded in larger personal, familial, professional and cultural systems, thus providing a unique perspective to the medical team. While health professionals or programs may identify the role of social work in varying ways, it is crucial that social workers, themselves, define their roles. This initiative helps raise awareness about the contribution they make to their patients and teams, particularly in times of flux within the health care system (Craig \& Muskat, 2013).

Traditionally, social work education for students interested in pursuing a career in health care has involved a combination of in-class teaching and hospital-based field instruction. However, with the current rapid pace of change within health care, there is the potential that in-class curriculum may not realistically reflect practice in the field. Along with new trends and demands faced by hospital social workers the development of specific core competencies is essential. Increased integration of academics and practice education is needed to equip new social workers with these necessary skills (Volland et al. 2003). Adaptation in how hospital social work practice is taught is considered important in order to emphasize this integration (Bronstein et al, 2007; DeBonis et al, 2015; Feldman, 2001).

In 2008, the Council on Social Work Education (CSWE, 2015) adopted a competency-based model of teaching focused on student learning outcomes for its Educational Policy and Accreditation Standards (EPAS). The goal of current educational programs in the United States is to develop content, approaches and educational activities that facilitate opportunities for students to demonstrate core competencies in their practice (CSWE, 2015). According to EPAS, practice is composed of competencies and behaviours

64 J. of Practice Teaching \& Learning 15(1), pp.63-80. @ w\&b 
based on knowledge, values, skills and cognitive and affective development (CSWE, 2015). In Canada, as well, the Standards for Accreditation of the Canadian Association for Social Work Education (CASWE-ACFTS) emphasize the requirement for a social work student to be 'equipped with knowledge and skills to competently perform various interactive practices such as engagement, assessment, intervention, negotiation, mediation, advocacy, and evaluation' (CASWE-ACTFTS, 2016).

Due to the changing Canadian health care environment, new approaches to teaching and learning may be required in order to bridge the gap between classroom and practice and continue to effectively meet these learning outcomes. University-agency partnerships are fundamental for providing classroom teaching that prepares students for the work required in practice settings. These linkages are important in hospital settings as social workers have assumed more complex duties, requiring skills in direct care, service coordination and advocacy.

Successful examples of university-agency partnerships in social work practice settings have been described in the literature (Bellamy et al. 2008; Clapton \& Forbes, 2012; Clapton et al., 2008; DeHart, 2013; Peleg-Oren et al, 2008). The Bringing Evidence for Social Work Practice (BEST) project paired university researchers with participants from three social service agencies in an effort to collaboratively incorporate evidence into practice (Bellamy et al., 2008). Similarly, the University of Edinburgh, in partnership with Glasgow Caledonian University, implemented a pilot project in which social work academic and practicum advisors worked alongside students during their placements in order to strengthen the integration of theory and practice into learning, while simultaneously reinforcing the university-agency partnership (Clapton \& Forbes, 2012; Clapton et al, 2008). A collaborative model was evaluated by DeHart (2013) outlining a partnership among staff at child welfare agencies, staff at colleges and universities and students. Participants reported that this collaboration was successful in 'infusing child welfare practice into higher education and infusing social work theory and evidence based principles into child welfare practice' (p. 752). Another investigation evaluated a Supplementary Education Model (SEM), comprising a series of study days collaboratively planned and implemented by students, academic advisors and field instructors and that focus on an issue related to social work in health care. The purpose of this model was to firmly integrate education in the field with that in academia (Peleg-Oren et al, 2008). Results revealed that study days were viewed as beneficial for both students in health care

65 J. of Practice Teaching \& Learning 15(1), pp.63-80. ๑ w\&b 
field placements and their field instructors, with $90 \%$ of participants rating the knowledge contribution and satisfaction gained from the study days positively (Peleg-Oren et al, 2008).

The purpose of this paper is to describe the development and evaluation of an elective course in social work practice in pediatric health care offered through a faculty of social work in a large Canadian university. The course was held onsite at a tertiary, urban pediatric teaching hospital that is affiliated with the University. The course consisted of weekly three hour seminars and featured lectures by the hospital social workers as well as a talk by a teenage patient and her mother and a lecture by a hospital bioethicist. The course was developed using the platform of the hospital's long-existing weekly student seminar series offered to practicum students. These seminars address issues related to social work and practice within a pediatric hospital. The course was developed using materials created by hospital social workers in delivering guest lectures in graduate courses at the university related to health care and practice with children and adolescents. The course aligned with both the Faculty and department's commitment to preparing students to become competent practitioners in pediatric health care settings.

Evaluation of the course consisted of exploring the experiences of Master of Social Work (MSW) students, as well as the pediatric hospital social work lecturers involved in the course. Research questions posed included: 1) What were the experiences of social work students who participated in the course? In particular, what was it like for students to attend the course on-site and be taught by practitioners? 2) What were the experiences of social work practitioners who taught the course? In particular, did they feel prepared to teach and did the teaching impact their ability to describe and critique their day-to-day work? 3) Can these experiences inform and improve future course delivery; if so, how?

\section{The course}

The course, Social Work Practice in Pediatric Health Care, was delivered onsite at a pediatric hospital. This setting allowed for learning to occur where practice actually takes place and included exposure to the sights, sounds and other sensory experiences related to a hospital setting. The course content was created and delivered by frontline social work practitioners

66 J. of Practice Teaching \& Learning 15(1), pp.63-80. @ w\&-b 
in pediatric health care, with the oversight and continual presence of the social work director, who is an assistant professor (status only) at the University. The course was offered weekly during the evenings for nine weeks in 2014. Each session was approximately three hours in length and involved two presentations. Sessions included didactic teaching, student participation and discussion.

The course comprised both broad and specific topics including theoretical concepts such as child and family centered care and interprofessional practice; bioethics; child and family response and adaptation to acute and chronic conditions; impact of childhood illness on the patient, parents and siblings; addressing trauma and end of life care; intersection of health and mental health issues; working with patients who have conditions associated with stigma; and common therapeutic approaches, such as group work, crisis intervention and supportive psychotherapy.

\section{Methods}

A qualitative approach to evaluation was used in this study, as qualitative research 'seeks answers to questions that stress how social experience is created and given meaning' (Denzin \& Lincoln, 2000, p. 8) and 'obtains the intricate details about phenomena such as feelings, thought processes and emotions that are difficult to extract or learn about through more conventional research methods' (Strauss \& Corbin, 1998, p. 11). The evaluation was undertaken to determine the experiences of students in the course as well as those of the instructors and to inform future teaching of the course. Interpretive description was used as the analytic framework for the study (Thorne et al, 1997; Thorn et al, 2004). Interpretive description is often used in small qualitative studies of clinical phenomena, focuses on understanding individuals' experiences and grounds these experiences within the context of health care. The ultimate goal of this framework is to generate ideas that contribute to clinical practice. A number of data sources were employed including anonymous data available from student course evaluations, demographic information and interviews with both students and social work practitioners who participated in the course.

67 J. of Practice Teaching \& Learning 15(1), pp.63-80. ๑ w\&b 


\section{Recruitment}

The study received research ethics approval from the ethics boards of both the hospital and the University. Eighteen social worker practitioners gave lectures or presentations and 23 students were enrolled in the course. The principal investigator contacted all staff and students through email after the final marks for the course were submitted to the University to explain the study and to provide the research coordinator's contact information. Interested participants were asked to respond directly to the research coordinator to mitigate conflict of interest and power dynamics, as the principal investigator also acted as coordinator of the course and is the director of the social work department. The research coordinator provided details about the study to participants and obtained informed consent.

\section{Sample}

All social worker presenters and students were asked to participate in this study; 18 social workers and 23 students were asked to participate. Ten social workers and four students consented to participate in the study (See Table 1 overleaf for participant characteristics). In addition, 11 students completed anonymous course evaluations. In a study employing interpretive description, sample sizes are relatively small and a sample of eight is considered sufficient for generating theme saturation (McCracken, 1988). All students were in their second year of the MSW program and all staff were frontline MSW-trained practitioners.

68 J. of Practice Teaching \& Learning 15(1), pp.63-80. ๑ w\&b 
Table 1

Participant Demographics

Social Workers $(N=10)$

Years in Social Work Field

6-10

2

11-19

6

$20+$

2

Years in Hospital

1-5

6-10

5

11-19

4

Age in Years

30-40

2

41-50

7

$51+$

1

Gender

Female

10

Students $(N=4)$

Social Work Program Status

Year Two

4

Specialization

Children and Families

1

Health and Mental Health

2

Gerontology

1

Age in years

20-30

3

31-40

1

Gender

Female

4

69 J. of Practice Teaching \& Learning 15(1), pp.63-80. (C) wEb 


\section{Data collection and analysis}

Participants completed a short demographic questionnaire and participated in an interview conducted by the research coordinator who has experience in qualitative interviewing. An interview guide was used which contained open-ended, semi-structured questions. Open-ended questions elicited rich description using the participants' own words, and gave them latitude to convey experiences and perceived needs relative to their individual perceptions and style of presentation, while being prompted to remain within the interview topics. An iterative process involved modifications to the interview guide throughout the process of data collection and analysis (Charmaz, 2006). All interviews were audio-tape recorded and transcribed verbatim by a contracted professional transcriptionist. The de-identified transcripts were then entered into NVivo 10, a qualitative data management and analysis software program (QSR International, 2012).

Interview transcripts were analyzed using McCracken's (1988) 'Long Interview' method of qualitative data analysis. Each transcript was read and themes (codes) were identified. Connections between codes were sought and assessed for how they may be described and expanded upon elsewhere within the same transcript. Codes were constantly compared with each other and across interview transcripts. Codes were combined and transformed into categories and emergent themes. Themes were then continually contrasted and reviewed.

To ensure methodological rigor, trustworthiness was established (Cresswell, 1998; Lincoln \& Guba, 1985). Establishing trustworthiness in qualitative research ensures credibility, confirmability, dependability, and transferability. Measures for ensuring quality and trustworthiness were employed including: prolonged engagement (the investigation team had considerable experience working within either the pediatric health care system, social work academia or both); negative case analysis (disconfirming or inconsistent cases relative to emerging phenomenon, themes or theoretical observations were sought) (Charmaz, 2006; Corbin, 2006); peer debriefing (team discussions examined ideas and possible preconceived notions among the investigation team), and thick description (themes included rich accounts and quotes that represented the actual voices of participants). Bias in the research team was examined individually and in team discussions through the use of reflexivity and bracketing.

70 J. of Practice Teaching \& Learning 15(1), pp.63-80. @ w\&b 


\section{Results}

Social workers and students identified strengths of the course as well as suggestions for improvement. Strengths identified by social workers included an enhanced sense of professional self, a positive impact of teaching on their daily work, and new opportunities generated from their participation. Students identified benefits such as having frontline workers provide a diverse and realistic view of the profession as well as the unique location of the course (the hospital). Both social workers and students made suggestions for improving the course. Social workers suggested that guidance around preparation of presentations would be helpful, as would feedback about their presentations. Suggestions from both social workers and students included scheduling of the course, increased interactive learning opportunities and increased coordination and articulation of a 'thread' to ensure integration and continuity of presentations and to limit repetition in classes throughout the course. Student course evaluations corroborated themes in the interviews including students finding value in learning from experienced practitioners, students developing an understanding of the role of social work within a hospital setting and comments about scheduling of the course. Themes from interviews are described in detail below.

\section{Strengths of the Course}

\section{Social worker experiences \& perceptions}

Enhanced sense of professional self

Many of the social workers reported that participation in the course increased their confidence in their professional practice / responsibilities and provided them with an opportunity to better articulate their roles. Social workers also commented that developing and presenting their lectures allowed them to appreciate the knowledge and skills that they possess and the unique value they bring to their clinical areas:

It was helpful for my practice... it made me aware that... I do have skills, I do have experience and I do have knowledge that other people may find useful... (social worker)

Impact on daily work

71 J. of Practice Teaching \& Learning 15(1), pp.63-80. ๑ w\&b 
Social workers described the impact of teaching on their daily work. Some social workers acknowledged that lecturing allowed them the opportunity to contemplate the planning of future presentations that they may conduct both in this context and when they teach and present in their daily roles. A few social workers reported that their participation allowed them to reflect on their daily practice, engage with students and consider the research connected to their clinical work. As noted by one social worker,

I noticed it really on a regular basis that I'm more...cognizant of...the theories of what I'm doing and, and it's really reassuring to have that in forefront again of what I am doing....

\section{Opportunity}

Social workers stated that their participation in the course provided them with new prospects, including the opportunity to do something outside of their daily roles:

I've been in the hospital here for a while now and so I get an opportunity to do something different and new, I generally like to take it or try it.

They also noted that participation provided the opportunity to collaborate with colleagues and reach professional or personal development goals

... any opportunity to do teaching, I love to do. Research, presentations, conferences, anything like that... that's part of my personal goals, it fit really well.

Social work participants also noted the opportunity to contribute to incoming social work students, as explained by one participant: 'It's. . .about kind of giving back as well....Paying it forward..... They spoke further about this motivation to give back:

I really appreciated people who, for my training, took time with me to do that, and so I haven't forgotten that and...I think it's important to take time to do that.

Social workers also spoke about the opportunity for students to learn from a diverse group of frontline social workers, as this provided a realistic understanding of the breadth of the field:

I think the greatest part about it is... we're looking at pediatric health care, you're

72 J. of Practice Teaching \& Learning 15(1), pp.63-80. @ w\&b 
bringing in day-to-day workers ... in this hospital there's so many different issues... cardiology ... eating disorders, looking at cancer patients, palliative care...you're really getting the full range of experiences... I think it's great for students.

\section{Student Experiences \& Perceptions}

Diversity

Students identified diversity as a significant benefit of taking the course. Similar to the social workers, students valued the fact that the frontline workers represented diverse areas of practice, years of experience and theoretical approaches:

... it was nice to hear from social workers, especially different social workers about their role; you could see that they were so drastically different.

Students expressed a preference for diversity in course content delivery and stated that multimodal forms of delivery led to higher levels of engagement. As one student explained:

.... One thing that was really amazing was...one week we had a patient from the hospital and her mom ... actually come to tell us about their experience, and what it was like and how they got through it and kind of their engagement with SickKids and that was really neat.

Realistic and practical description of the social work rol

Students found that learning from frontline workers encouraged a realistic understanding of the social work role in a hospital setting and solidified their desire to pursue this line of work. Students underscored that a highlight of the course was that the presenters offered content that focused on practical approaches they used in their own work:

I thought that, it [practitioners teaching] added... a real life perspective. The thing about a lot of professors is...they're removed from the field and I think it's good to have...people who really went to work that day and were able to give us great examples of families and the patients that they've had to deal with in the past. I think it [practitioners teaching]... definitely added a valuable component to it.

\section{Unique Format}

Students spoke of the unique construction of the course, with some noting having 'never experienced a course' like it. One student commented on the

73 J. of Practice Teaching \& Learning 15(1), pp.63-80. ๑ w\&bb 
rare opportunity presented by this course:

You know, this is such an [a]... unique opportunity to be able to speak with people who are practicing and... I don't know when else you really ever have that kind of opportunity...

As stated by another student:

....in the hospital you can observe the patients, the families, and, the nurse station...

I think it's exciting actually....That's the unique part.

\section{Suggestions for course enhancement}

Scheduling of course

Some participants (both social workers and students) found the timing of the course challenging, as it occurred in the evening, following a full day of practicum placements for students or regular work days for social workers. Some noted that this may have impacted the energy levels of students and wondered if a daytime course would address this issue.

\section{Interactive learning}

Both social workers and students stressed the importance of discussion, engagement and interaction. Some social workers suggested having families present about their experiences or having students shadow workers. Many participants suggested that interaction be incorporated into the sessions to a greater extent:

... I could have learned more if there was more conversation and discussion and... practical elements. I can give you an example?... So one week...we played kind of like a game, about, a patient we might see at the hospital and what's going on, and then as a class, we kind of talked about what the assessment would look like and what we might do and what the approach might be. So even just exercises like that, to get us talking, was really helpful, and maybe more of that kind of discussion, would have been better. (student)

As similarly noted by a social worker:

I feel like incorporating reflective practice into the delivery of the modules would be helpful and I know that that wasn't a formal part of it, if that was done, it was each practitioner bringing it, and I think the likelihood that each practitioner was

74 J. of Practice Teaching \& Learning 15(1), pp.63-80. ( $w \mathcal{E} b$ 
bringing that to the teaching sessions, is low.

Coordination of course content

Some social work and student participants suggested the need for greater coordination in course content, order of topics and themes presented. A few of the social workers noted that a logical order of themes may facilitate learning and some students thought that coordination of presentations may lead to a decrease in repetition of some material.

Preparation and feedback

It was suggested by some social workers that it would be helpful to have assistance with preparation prior to delivering a session, as would feedback following their presentations. Some social workers noted that guidance around structure, goals, and background of students may be helpful:

...in hindsight, it would have been nice to have a bit more...guidance as to what they're looking for. Cause I think it was pretty free, it was pretty open...Teach whatever you want to teach, you know, it'll be great. But it would have been nice to have a little more structure.

A number of social workers were interested in receiving feedback about their presentations as expressed by one social worker: 'I don't know if there could be feedback sheets given at the end of each session, but I think that would have been, I would have appreciated that, I think'.

\section{Discussion}

The field of hospital social work is continually shifting, challenging social workers to balance multiple roles, expectations and priorities. It may be a struggle however, to ensure that curriculum to prepare new social workers to enter the field keeps up-to-date and accurately reflects changes and implications for social work (Bronstein et al, 2007; Feldman, 2001).

The purpose of this study was to examine the experiences of social workers and students participating in a unique MSW elective course designed to bridge the gap between the university classroom and a pediatric health care setting. By exploring the experiences of both students and social workers, an understanding of the impact of the course, areas for

75 J. of Practice Teaching \& Learning 15(1), pp.63-80. @ w\&b 
improvement and suggestions for future innovative educational endeavors were attained. Collaboration in this course was beneficial for the University, the participating students, and the practitioners: the University gained an additional course to offer as an elective that integrates theory, research and practice, which is an integral aim of the Faculty; students gained an understanding of the diverse roles and challenges as well as the systemic value of social workers in pediatric health care settings; and practitioners enhanced their knowledge and skills in teaching, specifically with preparing and delivering material about their daily work.

Social workers in the study sample spoke of teaching as providing them with the opportunity to 'pay it forward' to a new generation of professionals, do something outside of their daily roles and feel validated in their expertise. Similar findings have been reported in the medical field with general practitioners acting as preceptors to undergraduate medical students. A study by May Mand et al. (2012) found that physicians were motivated to teach students through the desire to transfer knowledge and improve education. They also viewed students gaining a realistic idea of their work to be a benefit. Hartley et al. (1999) found that teaching allowed family practitioners to add variety to their daily work, enhance confidence in their teaching skills and increase reading and reflection in their clinical practices. Insight into the motivating factors and benefits for frontline workers involved in educating students can help to encourage commitment to teaching as well as identify their professional development needs as they assume the role of educators. Further research on frontline workers as educators across clinical settings is recommended to augment this knowledge base.

Students found learning from frontline practitioners to be an opportunity grounded in realistic and practical knowledge of the social work profession. They also gained a real-time conceptualization of hospital social work, which was unique. Some students especially valued learning about practical approaches used by the practitioners and felt that the incorporation of these types of approaches into the course should be enhanced. This finding is especially interesting when considering the fit between curriculum and student needs. Heggen (2008) found that Norwegian social work students placed a low value on academic knowledge at the start of their educational careers and that this trend continued to decline throughout their programs and three years into their practices. Furthermore, respondents reported that relational and practical knowledge was of greater importance in their daily work; however they did not necessarily gain these competencies

76 J. of Practice Teaching \& Learning 15(1), pp.63-80. @ w\&b 
in their academic programs to the extent they would have preferred. Similarly, Hessenauer (2011) found that newly practicing social workers found 'hands-on' aspects of their curriculum to be particularly beneficial in their current work as social workers. These findings may be significant to educational administrators when developing course content. In the current course, students were able to learn directly from frontline practitioners in the setting where practice takes place, thus providing an applied, real-world learning experience. Additional research is recommended to develop best practices to ensure the currency and reflectiveness of educational content to current practice, policy and contextual changes.

\section{Future Plans}

The findings of this study suggest that content of this course was delivered in a novel way and setting by providing unique learning opportunities for students and staff alike. Continuing to offer the course will provide ongoing opportunities to strengthen the University-hospital partnership, bridge the gap between classroom and practice for students, and provide unique professional development opportunities for social workers.

A number of factors should be considered when planning future course delivery. As recommended by some social workers, additional support and guidance during preparation of presentations may be helpful. Course coordinators could meet with all staff to discuss structure and expectations of presentations and to offer feedback after each presentation. This would address the participants' recommendation that there was a need for enhanced coordination among presentations. It is highly recommended that course coordinators make explicit the common 'thread' throughout the course content, and provide clear guidance and expectations to presenters to make links to the 'thread'. Finally, social workers and students were in agreement about the benefit and need for increased interactive and experiential modalities in content delivery, along with allowing time for reflection and discussion.

\section{Limitations}

There were limitations associated with this study. Recruitment and enrolment were unable to commence prior to grade submissions. This time

77 J. of Practice Teaching \& Learning 15(1), pp.63-80. () w\&b 
delay may have resulted in limited recall from participants around details of the course content. It also may have been a factor that contributed to the difficulty recruiting students, as many were well into their practicum placements at the time of recruitment. Student enrolment in the study was particularly low, reflecting a significant loss of additional data related to student perspectives of this course.

\section{Conclusions}

The course discussed in this paper introduced an innovative learning opportunity in social work education. Delivering a course in an agency setting with practitioners teaching provided a unique opportunity for integration of academics and practice, and for the delivery of content. The course aligned with the Faculty's mission of integrating practice into research and research into practice. The course also aligned with the hospital's goal of bridging the theory-practice gap for students, and contributed to the hospital's already rigorous education program. The aim is to continue to develop this form of education. This course offered students a valuable opportunity to be introduced to the field in a forum that is representative of both the challenges and value of working in a pediatric hospital setting.

\section{References}

Bellamy, J. L., Bledsoe, S. E., Mullen, E. J., Fang, L., and Manuel, J. I. (2008) Agency-university partnership for evidence-based practice in social work. Journal of Social Work Education, 44, 3, 55-76

Bronstein, L., Kovacs, P., and Vega, A. (2007) Goodness of fit: Social work education and practice in health care. Social Work in Health Care, 45, 2, 59-76

Canadian Association for Social Work Education (2014) CASWE-ACFTS Standards for Accreditation, Retrieved from http://caswe-acfts.ca/wp-content/ uploads/2013/03/CASWE-ACFTS-Standards-11-2014.pdf

Charmaz, K. (2006) Constructing Grounded Theory: A practical guide through qualitative analysis. London: Sage Publications

Clapton, G., and Forbes, R. (2012) Barefoot tutors? Navigating the barriers between

78 J. of Practice Teaching \& Learning 15(1), pp.63-80. ๑ w\& b 
student, university and field in social work education. The Journal of Practice Teaching and Learning, 9, 1, 5-19

Clapton, G., Cree, V. E., Allan, M., Edwards, R., Forbes, R., Irwin, M., and Perry, R. (2008) Thinking 'outside the box': A new approach to integration of learning for practice. Social Work Education, 27, 3, 334-340

Corbin, J. and Strauss, A. (2008) Basics of Qualitative Research: Techniques and procedures for developing grounded theory. (3rd ed.) Thousand Oaks, CA: Sage

Council on Social Work Education (2008) Educational Policy and Accreditation Standards. Retreived from http://www.cswe.org/File.aspx?id=13780

Craig, S. and Muskat, B. (2013) Bouncers, brokers and glue: The self-described roles of social workers in urban hospitals. Health and Social Work. 38, 1, 7-16

Cresswell, J.W. (1998) Qualitative Inquiry and Research Design: Choosing among five traditions. Thousand Oaks, CA: Sage

DeBonis, J.A., Becker, M.A., Yoo, J., Capobianco, J. and Salerno, A. (2015) Advancing social work education: Lessons learned from piloting an integrated healthcare curriculum. Journal of Social Service Research, 41, 594-621

DeHart, D. (2013) Perfecting the craft: Formative assessment of a university-agency partnership for social work education. Social Work Education, 32, 6, 748-761

Denzin, N. K. and Lincoln, Y.S. (2000) The discipline and practice of qualitative research. in N.K. Denzin and Y.S. Lincoln (Eds.) Handbook of qualitative research, second edition. Thousand Oaks: Sage

Earls Larrison, T., and Korr, W. S. (2013) Does social work have a signature pedagogy?. Journal of Social Work Education, 49, 2, 194-206

Feldman, R. A. (2001) Health care and social work education in a changing world. Social work in health care, 34, 1-2, 31-41

Hartley S, MacFarlane F, Gantley M, Murray E (1999) Influence on general practitioners of teaching undergraduates: Qualitative study of London general practitioner teachers. BMJ, 319, 1168

Heggen, K. (2008) Social workers, teachers and nurses-from college to professional work. Journal of Education and Work, 21, 3, 217-231

Hessenauer, S. L. (2011) From classroom to workplace: Becoming a social worker. Dissertations. Paper 22. http://e common s.luc.edu/luc_d iss/22

Lincoln, Y.S. and Guba, E.G. (1985) Naturalistic Inquiry. Newbury Park, CA: Sage McCracken, G. (1988) The Long Interview. Thousand Oaks, CA: Sage

May, M., Mand, P., Biertz, F., Hummers-Pradier, E., and Kruschinski, C. (2012) A survey to assess family physicians' motivation to teach undergraduates in their practices. PloS one, 7, 9, e45846

Peleg-Oren, N., Aran, O., Even-Zahav, R., Molina, O., and Stanger, V. (2008) Supplementary Educational Model (SEM) in social work education for health

79 J. of Practice Teaching \& Learning 15(1), pp.63-80. @ w\&-b 
care settings. Social Work in Health Care, 47, 3, 306-319

Strauss A. and Corbin J. (1998) Basics of Qualitative Research: Grounded theory procedures and Techniques (2nd ed.): Thousand Oaks, CA: SAGE Publications Inc

Thorne, S., Kirkham, S. R., and MacDonald-Emes, J. (1997) Focus on qualitative methods. Interpretive description: a noncategorical qualitative alternative for developing nursing knowledge. Research in Nursing \& Health, 20, 2, 169-177

Thorne, S., Reimer Kirkham, S. and O'Flynn-Magee, K. (2004) The analytic challenge in interpretive description. International Journal of Qualitative Methods, 3, 1, Article 1. http://www.ualberta.ca/ iiqm/backissues/3_1/pdf/thorneetal. pdf

Volland, P. J. (1996) Social work practice in health care: Looking to the future with a different lens. Social work in health care, 24, 1-2, 35-51

Volland, PJ; Berkman, B.; Phillips, M., and Stein, G, (2003) Social work education for health care. Social Work in Health Care. 37, 4, 1-17

Wayne, J., Bogo, M., and Raskin, M. (2010) Field education as the signature pedagogy of social work education. Journal of Social Work Education, 46, 3, 327-339

QSR International. (2012) NVivo (Version 10) [Software]. Available from http:// www.qsrinternational.com/products_nvivo.aspx

80 J. of Practice Teaching \& Learning 15(1), pp.63-80. ๑ w\&b 
Copyright of Journal of Practice Teaching \& Learning is the property of Whiting \& Birch Limited and its content may not be copied or emailed to multiple sites or posted to a listserv without the copyright holder's express written permission. However, users may print, download, or email articles for individual use. 